\title{
Morphological factors influence on young women arterial pressure levels
}

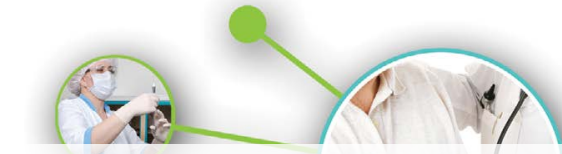

Many studies point to the correlation between the physical development indexes and functioning of the cardiovascular system. At the same time, the problem of the correlation between the morphological parameters of arterial pressure in the group of healthy young women is not studied enough.

\section{KEYWORDS: arterial pressure, ovarian-menstrual cycle, typology, muscle component.}

\section{Introduction}

A human being as a biological specie has a high level of the morphological and functional variability [1-5,9]. A number of works were devoted to researching the age and sex regularities $[1,17,18]$.

In the process of the body growth and development the cardiovascular system abilities are significantly altered, the correlation between the central and autonomic regulation of the cardiac rhythm is optimized, complex mechanisms of cardiac control are improved [6-11,20].

Many studies indicate existing of the correlation between the physical development and the functioning indices of the cardiovascular system (CVS) - heart rate (HR), systolic (SAP) and diastolic (DAP) arterial pressure $[12,13]$.

Thus in some works $[14,19]$ the presence of the reliable positive correlation between the physical development parameters and arterial pressure is shown. There are also data on revealing these values of the sympathy-parasympathetic balance (LF/HF) of obese subjects compared to the control group with the BMI (body mass index) within the physiological norm [14]. At the same time, the nature of these correlations and health assessment prospects are debatable. The problem of the correlation between morphological parameters and arterial pressure of healthy young women is practically not researched and the nature of this correlation is almost not defined.

\section{Methods}

The study was conducted in compliance with the basic bioethical provisions of the Council of Europe Convention on Human Rights and Biomedicine (of April 4. 1997), Helsinki declaration of the World medical association on ethical principles of conducting scientific medical investigations with participation of humans (1994-2008), and the Order of the Ministry of Health Protection of Ukraine № 690 of September 23. 2009.

Measuring was carried out on 77 women aged 1819 years in conditions close to the state of the basic metabolism in the prone position at rest, during tilt test and during the psycho - emotional loading using Makarenko's method [13]. Every tested woman was investigated three times: during the follicular phase (I), ovulation (II) and luteal phase (III) of ovarian-menstrual cycle (OMC). Defining the phases of the cycle was carried out according to the anamnesis, basal temperature measurement and applying the set of ovulation jet tests «Solo» (IND Diagnostic. Inc. Canada).

\section{- Analytical methods}

Systolic (APs) and diastolic (APd) arterial pressure was measured by the Korotkov's method by a mercury tonometer (Riester. Germany). Mean arterial pressure (APm) was calculated with Hickam formula.

Anthropometric indices were measured by the method of Bunak [4] taking into account the methodical recommendations of Martirosov

\section{Olena Lutsenko*}

Hlukhiv Oleksandr Dovzhenko National Pedagogical University, Ukraine

*Author for correspondence:

olena85/utsenko@gmail.com 
[14]. The research protocol included measuring the following parameters: body weight, body height, chest girth, thickness of 7 skin fat folds. Standard tools were used for measuring relevant anthropometric indicators. The thickness of skin fat folds was measured by a caliper with a constant pressure of $10 \mathrm{~g} / \mathrm{mm} 2$ under the shoulder blade, over the triceps, biceps, on the abdomen, chest, forearm, thigh and shin. The body mass was separated for fat, muscle and bone components according to the formulas [4]. Weight and height correlation was assessed by way of applying the body mass index (BMI or Kettle index) which was calculated with the following formula: BMI=Mass $(\mathrm{kg}) /$ height $\left(\mathrm{m}^{2}\right)$, which norm is $18.5-24.9 \mathrm{~kg} / \mathrm{m}^{2}$ according to the World Health Organization classification. Rorer Index (RI or body density index $\mathrm{kg} / \mathrm{m}^{3}$ ) was calculated with the following formula: $\mathrm{RI}=$ Weight $(\mathrm{kg}) /$ Height $\left(\mathrm{m}^{3}\right)$, which norm is $1.16-1.30 \mathrm{~kg} / \mathrm{m}^{3}$. For calculating body area as one of the important physical development indices Isakov formula was applied [19].

\section{- Statistical methods}

All the results of the anthropometric study were calculated by the methods of variational statistics. Commonly accepted indicators were calculated: arithmetic mean $(\mathrm{M})$, mean square deviation (SD). The reliability of differences between values in different OMC phases was estimated by means of Wilcoxon Paired Comparison and Student's t-test. The relationship between indicators was calculated by the nonparametric Spearman correlation coefficient (Glantz 2012).

\section{Results and discussion}

It is generally accepted that arterial pressure is an important homeostatic index of the body. In the prone position the indices of APs. APd and APm were respectively $99.93 \pm 0.62 \mathrm{~mm}$ of mercury, $64.43 \pm 0.43 \mathrm{~mm}$ of mercury and $76.13 \pm 0.40$ $\mathrm{mm}$ of mercury. During the tilt test these indices credibly increased $(\mathrm{p}<0.001)$. Credible increasing of AP compared to levels in prone position at rest $(\mathrm{p}<0.001)$ was also observed during the psycho emotional loading [10-12,18].

One of the factors causing such variability of both levels and reactivity of AP of women in different phases of the ovarian-menstrual cycle and under different conditions is their morphological indices. To find out the influence of morphological parameters on AP levels the factor analysis was carried out which results made it possible to allocate three factors with their own values exceeding 1 (TABLE 1).

The first factor was mostly determined by the chest girth, body weight, fat component, muscle component, body area. Rorer and Kettle indices, relative weight of the muscle component (factor of loading were $0.78,0.97,0.68,0.93,0.95$, $0.95,0.83,-0.96$ respectively).

The second factor was determined by the fat component, bone component, relative weight of the fat and bone components (factor loads $0.73,0.83,0.96$, and 0.98 respectively).

The third factor was determined by the body height. Its factor load was- 0.99.

Thus, the peculiarities of AP in women group with different levels of relative weight of the muscular component were analyzed.

The histogram analyses of distributing the relative mass of the muscle component in the group of healthy young women (FIGURE 1) showed that there exist several typological

Table 1. Results of the factor analyses of women's morphometric indices (18-19 years) by the method of the main components with rotating Biquartimax.

\begin{tabular}{|c|c|c|c|}
\hline Indices & Factor 1 & Factor 2 & Factor 3 \\
\hline Chest girth & 0.78 & 0.08 & 0.00 \\
\hline Body heihgt & 0.01 & -0.04 & -0.99 \\
\hline Body weight & 0.97 & 0.11 & -0.05 \\
\hline Fat component & 0.68 & 0.73 & -0.01 \\
\hline Muscle component & 0.93 & 0.09 & -0.08 \\
\hline Bone component & 0.53 & 0.83 & 0.00 \\
\hline Body area & 0.95 & 0.08 & -0.06 \\
\hline Kettle index & 0.95 & 0.16 & 0.06 \\
\hline Rorer index & 0.83 & 0.17 & 0.12 \\
\hline Relative weight of fat component & 0.23 & 0.96 & 0.01 \\
\hline Relative weight of muscle component & -0.96 & -0.03 & -0.04 \\
\hline Relative weight of bone component & -0.12 & 0.98 & 0.04 \\
\hline Proper indices of factors & 6.63 & 3.20 & 1.01 \\
\hline Part of general variability & 0.55 & 0.27 & 0.08 \\
\hline
\end{tabular}


groups in the researched sample. That is why three groups were distinguished: with low component - less than $37.25 \%$, middle - from $37.25 \%$ to $38.25 \%$ and high - over $38.25 \%$.

TABLE 2 represents the indices of the arterial pressure levels under different conditions for women with different muscle component values. So, in the prone position at rest we marked a significant decrease of APm in extreme groups, namely $<37.25 \%$ and $>38.25 \%$. While changing the position for standing changes occurred in group $>38.25 \%$ by the values of APs and APm. Under conditions of the psycho - emotional loading changes in the extreme groups were also observed. Close interconnection between the component and pressure is confirmed by the researches of the other authors $[5,7,8,15,16]$.

Defined by us and the other authors connection between the morphometric and hemodynamic indices allows us to assume that individuals with the extreme types of the muscular component values can demonstrate tension in regulating the cardiovascular system.
Reactivity of the arterial pressure indices at the tilt test was the same for people with different levels of muscle component. Concerning the psycho-emotional loading women with higher level of muscle component (over 38.25\%) have less changes of the arterial pressure compared with women with the average muscle component indices. So, herewith the reactivity indices were the following: APs- $4.20 \mathrm{~mm}$ of mercury; APd - $-4.15 \mathrm{~mm}$ of mercury; APm - $-4.72 \mathrm{~mm}$ of mercury with the muscle component of 37.25$38.25 \%$ and APs - $-3.58 \mathrm{~mm}$ of mercury; APd - $-2.31 \mathrm{~mm}$ of mercury and APm - $-3.02 \mathrm{~mm}$ of mercury with the component level over $38.25 \%$.

The AP levels and their reactivity can be influenced by the functional altering the female body in the different of the ovarian-menstrual cycle phases FIGURE 2.

In the prone position at rest APs credibly increased in phases II and III compared with phase I: difference between phase I and II was $0.39 \pm 0.21$ $\kappa \mathrm{Pa}(\mathrm{p}<0.05)$, while difference between phases I and III was $-0.47 \pm 0.20 \kappa \mathrm{Pa}(\mathrm{p}<0.05)$. During

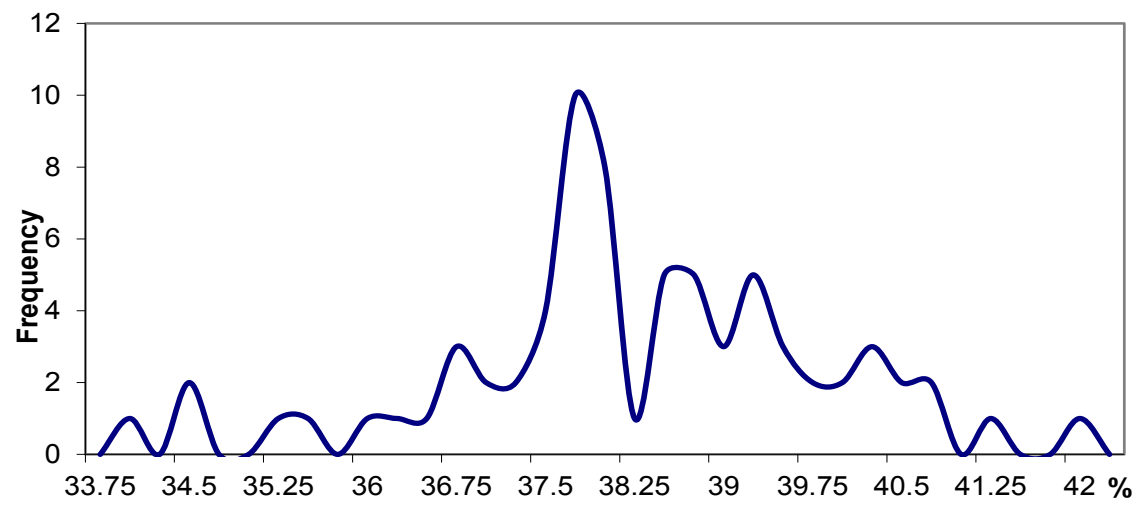

FIGURE 1. Histogram of distributing the relative mass of the muscle component in the researched group of healthy young women.

\begin{tabular}{|c|c|c|c|}
\hline \multirow[t]{2}{*}{ Muscle component. \% } & $\begin{array}{c}\mathrm{AP}_{\text {syst. }} \\
\text { mm of mercury }\end{array}$ & $\begin{array}{c}\mathrm{AP}_{\text {diast }} \\
\mathrm{mm} \text { of mercury }\end{array}$ & $\begin{array}{c}\mathrm{AP}_{\text {mean }} \\
\mathrm{mm} \text { of mercury }\end{array}$ \\
\hline & \multicolumn{3}{|c|}{ Prone position at rest } \\
\hline less than $37.25 \%$ & $100.33 \pm 1.16$ & $65.11 \pm 0.96$ & $76.90 \pm 0.91^{*}$ \\
\hline $37.25-38.25 \%$ & $98.83 \pm 1.03$ & $63.58 \pm 0.78$ & $74.98 \pm 0.60$ \\
\hline over $38.25 \%$ & $100.89 \pm 1.06$ & $64.89 \pm 0.64$ & $76.85 \pm 0.67^{*}$ \\
\hline \multicolumn{4}{|c|}{ Tilt test } \\
\hline less than $37.25 \%$ & $105.78 \pm 1.46$ & $67.11 \pm 0.83$ & $80.00 \pm 0.84$ \\
\hline $37.25-38.25 \%$ & $103.33 \pm 1.11$ & $66.60 \pm 0.57$ & $78.85 \pm 0.66$ \\
\hline over $38.25 \%$ & $105.67 \pm 1.05^{*}$ & $67.41 \pm 0.62$ & $80.16 \pm 0.61^{*}$ \\
\hline \multicolumn{4}{|c|}{ Psycho-emotional loading } \\
\hline less than $37.25 \%$ & $101.79 \pm 1.42$ & $65.60 \pm 0.69$ & $77.66 \pm 0.82^{*}$ \\
\hline $37.25-38.25 \%$ & $99.74 \pm 0.87$ & $64.62 \pm 0.49$ & $76.32 \pm 0.51$ \\
\hline over $38.25 \%$ & $102.83 \pm 1.02^{*}$ & $65.83 \pm 0.61$ & $78.17 \pm 0.61^{*}$ \\
\hline
\end{tabular}




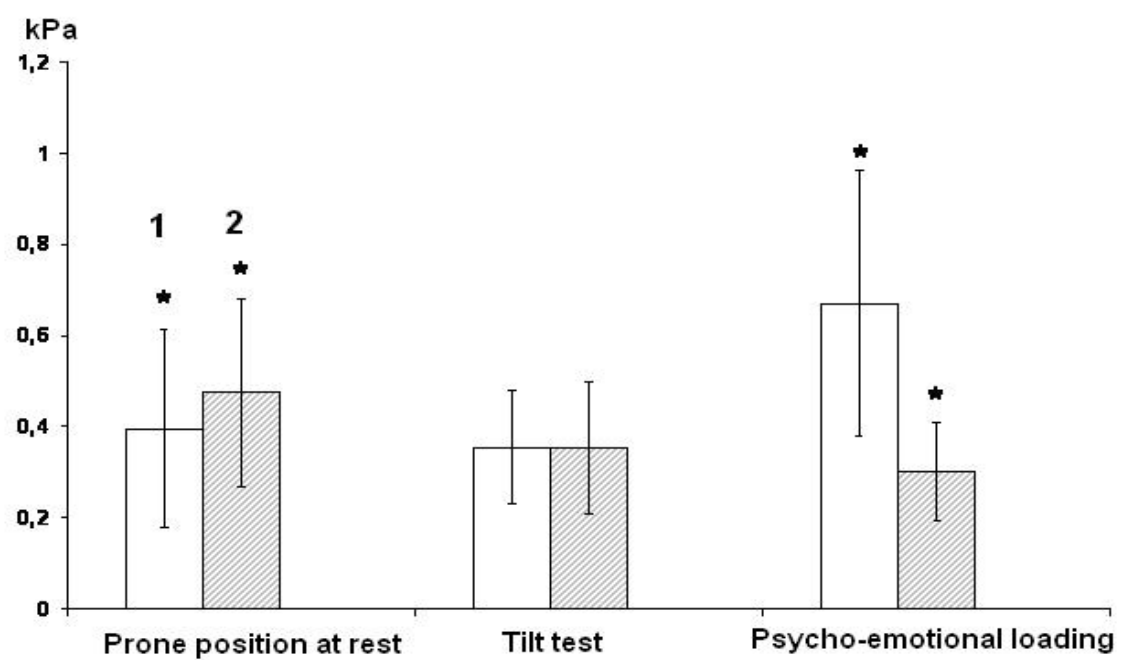

FIGURE 2. Changes of mean arterial pressure in ovulation (1) and luteal (2) phases of ovarian-menstrual cycle compared with follicular phase; * $p<0.05$ compared to follicular phase.

the tilt test increasing the APs was observed in phase I and II, while in phase III the changes were not statistically significant. Herewith the difference of APs in phase I-II was $-0.35 \pm 0.12 \mathrm{\kappa Pa}$ and in phases I-III it was $0.35 \pm 0.14 \mathrm{KPa}$.

It is obvious that increasing the arterial pressure is due to reducing the length of the peripheral vessels, and the result of it is increasing the pressure in the vessels of the lower limbs $[12,15]$. The mechanism of compensatory reacting the tilt test is due to changes in the activity of baroreceptors in response to changes in the arterial pressure, inhibiting the vagal influence and increasing the sympathetic influence on the heart and blood vessels [17-20]. With the psycho emotional loading the level of APs in phase III compared to that in phase I was leveled $(\mathrm{p}<0.05)$. Herewith the difference index of APs made: $0.67 \pm 0.20 \kappa \mathrm{Pa}(\mathrm{p}>0.05)$ and $0.30 \pm$ $0.10 \kappa \mathrm{Pa}$ respectively.

So, the arterial pressure reacting on such a load is characterized by certain peculiarities and there is an increase in the level of the arterial pressure in the ovulation and even more in the luteal phase of the ovarian-menstrual cycle compared to the follicular phase [6].

For women with different levels of muscle component the peculiarities of the arterial pressure in different phases of the ovarianmenstrual cycle and in different conditions were identified FIGURE 3.

In the prone position at rest the arterial pressure credibly increased in phase II with the muscle component level $<37.25 \%$ and its index was $-1.20 \mathrm{~mm}$ of mercury $(\mathrm{p}<0.05)$. With the component level of $37.25-38.25 \%$ the valid changes in the average arterial pressure were observed both in phase II and III and their indexes were respectively: $-0.07 \mathrm{~mm}$ of mercury and $0.37 \mathrm{~mm}$ of mercury $(\mathrm{p}<0.05)$. On condition of increasing the muscle component level $>38.25 \%$ the valid changes of the average arterial pressure were not observed in any phase.

During the tilt test the following situation was observed: with the component level $<37.25 \%$ the average arterial pressure index was $-1.11 \mathrm{~mm}$ of mercury $(\mathrm{p}<0.05)$. With the component level $37.25-38.25 \%$ the valid changes of the average arterial pressure were observed both in the II and III phases and their indexes were $0.457 \mathrm{~mm}$ of mercury and $0.90 \mathrm{~mm}$ of mercury respectively $(p<0.05)$. On condition of increasing the muscle component level $>38.25 \%$ the valid changes of the average arterial pressure were not observed.

During the psycho - emotional loading the average arterial pressure level changed only in phase II with the muscle component level $<37.25 \%$ compared with phase I while its index was -1.55 . Consequently, the arterial pressure reacting to such a load is characterized by certain peculiarities and all of them are characterized by changes in the arterial pressure in the ovulation and even more in the luteal phase of the ovarianmenstrual cycle compared with the follicular one.

It is obvious that the increase in the arterial pressure is due to reducing the length of the peripheral vessels leading to increased pressure in the vessels of the lower limbs $[2,11]$. The mechanism of the compensatory reaction to tilt test is due to changes in the activity of baroreceptors responding to changes in the 


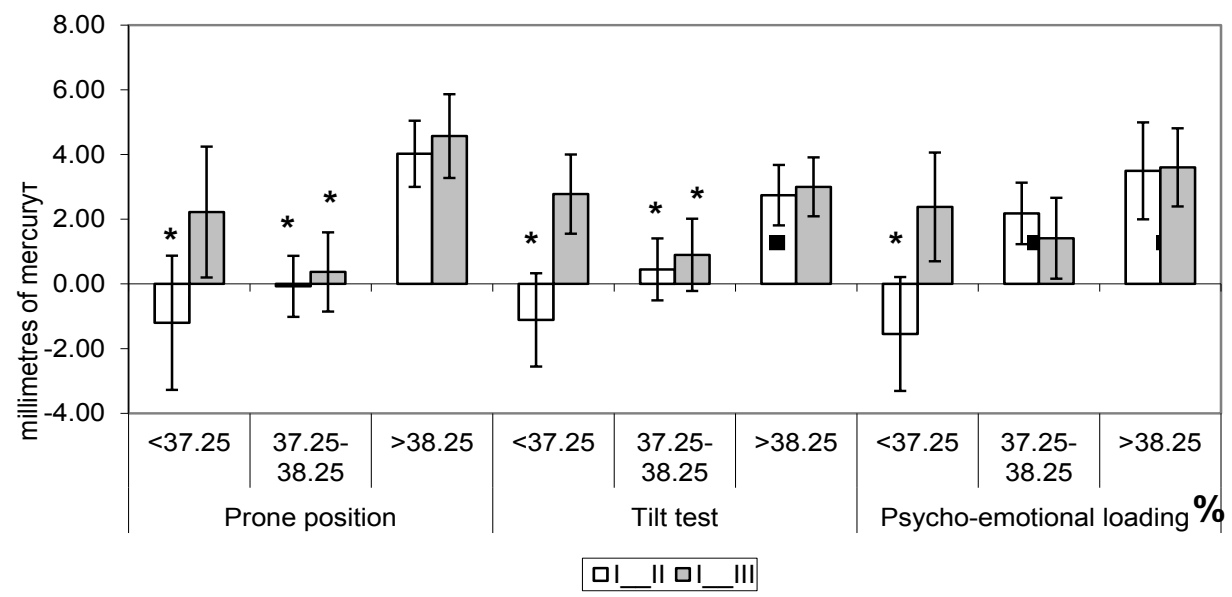

FIGURE 3. Changes in the average arterial pressure in the ovulation (II) and luteal (III) phases of the ovarianmenstrual cycle compared to the follicular phase (I) for women with different muscle component levels; ${ }^{*} p<0.05$ compared with the group with the relative muscle mass $>38.25 \%$.

arterial pressure. Inhibiting the vagal and increasing the sympathetic influence on the heart and blood vessels $[3,12]$. Similar adaptive changes are of the compensatory nature and are likely to contribute to the increased pressure during the tilt test.

\section{Conclusions}

1. It was concluded that in the state of rest and during the psycho-emotional loading women had changes in the levels of the arterial pressure average in phases II and III of the ovarian cycle compared to phase I.

2. Analysis of the histogram of distributing the relative muscle component weight of healthy young women allowed distinguishing several typological groups in the researched sample.

3. Changes in the average arterial pressure in phases II and III of the ovarian-menstrual cycle were detected in comparison with phase I for women with different levels of muscle component in the prone position at rest and during the tilt test. 
References

Antelmi I, Paula R, Shinzato AR, et al. Influence of age, gender, body mass index.,and functional capacity on heart rate variability in a cohort of subjects without heart disease. Am. J. Cardiol. 3 (93), 381-385 (2004).

Bernardi L, Leuzzi S, Radaelli A, Johnston J. Low-frequency spontaneous fluctuations of $\mathrm{R}-\mathrm{R}$ interval and blood pressure in conscious humans: a baroreceptor or central phenomenon. Clin. Sci. 87(6), 649-654 (1994).

Brunt Ve, Miner JA, Kaplan PF, et al. Short-term administration of progesterone and estradiol independently alter carotidvasomotor, but not carotid-cardiac, baroreflex function in young women. Am. J. Physiol. Heart Circ. Physiol. 305, 1041-1049 (2013).

Bunak VV. Anthropometry. Moscow. GIPN of the RSFSR $364 \mathrm{p}$ [Russian] (1941).

Capuano V, Bambacaro A, Arminio $\mathrm{TD}$, et al. Correlation between body mass index and others risk factors for cardiovascular disease in women compared with men. Monaldi Arch. Chest. Dis. 4 (60), 295-300 (2003).

Dimitriyev DA, Sapyerova YV, Dimitriyev AD, Karpenko YD. Features of the functioning of the cardiovascular system in different phases of the menstrual cycle: the Russian Journal of Physiology. THEM. Sechenova. 93(3), 300-305 [Russian] (2007).
Furman YM, Vasylenko DA, Ocheretna OL. Osoblyvosti korelyatsiynykh zvyazkiv pokaznykiv variabel'nosti sertsevoho rytmu $\mathrm{z}$ antropometrychnymy pokaznykamy u pidlitkiv riznykh somatypiv. Visnyk Morfolohiyi. 14 (1), 42-46 [Ukrainian] (2008).

Jackson AS, Pollock ML, Ward A. Generalized equations for redicting body density of women. Med. Sci. Sports Exerc. 12, 175-182 (1980).

Kontosić I, Mesaros-Kanjski E, BozinJuracić J, et al. Some anthropometric characteristics, reactions on physical stress, and blood pressure in males aged 18 in "Primorsko-Goranska» County. Croatia. Coll. Antropol. 1 (25), 31-39 (2001).

Kovalenko SO, Kudij LI, Lutsenko OI. Peculiarities of male and female heart rate variability. Sci. Edu. New Dimension. 1(2), 17-20 (2013).

Kovalenko SO, Lutsenko OI. Osoblyvosti tsentral'noyi hemodynamiky ta yiyi khylyovoyi struktury u zhinok v stani spokoyu ta pry ortoprobi v rizni fazy ovarial'nomenstrual'noho tsyklu. Visnyk problem biolohiyi i medytsyny: № 1 (98), 278-281 [Ukrainian] (2013).

Lutsenko OI, Kovalenko SO. Blood Pressure and Hemodynamics: Mayer Waves in Different Phases of Ovarian and Menstrual Cycle in Women. Physiol. Res. 66, 235-240 (2017)

Makarenko MV. A method for performing a study and assessment of the individual neurodynamic properties of human higher nervous activity. Fiziol Zh. 45, 125-131 [Ukrainian] (1999).

MartirosovEG, Nikolayev DV, Rudnyev OG. Nonnology and methods for determining the composition of the human body. Moscow: Nauka Publishers. 248p [Russian] (2006).

Mohrman DE, Heller LJ. Cardiovascular Physiology. Mcgraw-Hill: Lange Medical Books. 257 p (2002).

Muscelli E, Emdin M, Natali A, et al. Autonomic and hemodynamic responses to insulin in lean and obese humans. J. Clin. Endocrinol. Metab. 6 (83), 2084-2090 (1998).

Nikolayev VG, Nikolayeva NN, Sindeyeva LV, Nikolayeva LV. Anthropological examination in clinical practice. Krasnoyarsk: Publishing house «Verso» 173 p [Russian] (2007).

Princi T, Parco S, Accardo A, Radillo $O$ : Parametric evaluation of heart rate variability during the menstrual cycle in young women. Biomed. Sci. Instrum. 41, 340-345 (2005).

Prokashko IY. Individual-year dynamics of physiological functions in females. For the degree of candidate of medical sciences. 27 [Russian] (2005).

Ravisankar P, Udupa K, Prakash E. Correlation between body mass index and blood pressure indices. Handgrip strength and handgrip endurance in underweight. Normal weight and overweight adolescents. Indian J. Physiol. Pharmacol. 4 (49), 455-461 (2005). 